\title{
A test of nerve conduction to muscles of the shoulder girdle as an aid in the diagnosis of proximal neurogenic and muscular disease
}

\author{
M. M. GASSEL ${ }^{1}$ \\ From the Department of Clinical Neurophysiology, University Hospital, Copenhagen, Denmark
}

The involvement of the nerves to proximal muscles in the course of polyneuritis or in mononeuritis is not easily evaluated, and the differentiation of neuritis from other causes of proximal muscular weakness and wasting may be difficult. An indirect test of nerve conduction to proximal muscles of the upper extremity is therefore reported. The latency of response is measured on proximal stimulation of the nerve trunk (at Erb's point) to recordings made from concentric needle electrodes situated in the particular muscles at various distances from the point of stimulation. The normal range of values is presented, the relationship of the findings to neuromuscular anatomy is discussed, and the results in a series of patients with various diseases of proximal nerves and muscles are reported. It will be shown that the examination is of assistance in the diagnosis of neuritis of the nerves to proximal muscles.

\section{METHODS AND MATERIALS}

The trunks of the brachial plexus were stimulated a few centimetres above the clavicle in the angle between the posterior border of the sternomastoid muscle and the clavicle at about the level of the sixth cervical vertebra (Erb's point).

The recording electrodes were placed on a vertical line at progressive distance from the point of stimulating in the middle of each of the muscles examined. Two electrodes were placed in the supraspinatus and infraspinatus muscles, and three in the deltoid, biceps, and triceps.

The stimulating electrode was a bipolar surface electrode with a diameter of $6 \mathrm{~mm}$. for each electrode and a centre-to-centre separation of $25 \mathrm{~mm}$. (DISA 13K62). The surface of the skin was prepared by gentle abrasion and rubbing with ether. A thin flat lead plate, ground $3 \times 8 \mathrm{~cm}$., was placed between the stimulating and recording electrodes. The stimulator had a maximal primary voltage of $50 \mathrm{~V}$ and transformer output with a ratio of $1: 1 \cdot 5$. The output impedance of the transformer was 15 k.ohms (DISA Multistim). The stimulus pulse dura-

${ }^{1}$ Holder of a research fellowship from the Muscular Dystrophy Associations of America Inc. tion was $0.7 \mathrm{~m} . \mathrm{sec}$. and the frequency 1 per second. The recording electrodes were three concentric needles with a diameter of $0.45 \mathrm{~mm}$. and a leading-off surface of $0.07 \mathrm{~mm} .^{2}$ (DISA 13K50). Simultaneous recordings from the three electrodes were amplified and displayed on the्ट three independent cathode ray tubes of the electromyograph (DISA). The time base was 1 msec. pe्d millimetre.

The stimulus voltage at threshold for a motor response was first determined and then a maximal response of tained using a stimulus voltage which was at least twide that of the threshold stimulus. The amplification $7 a s$ adjusted to visualize the entire action potential com

Five to 10 photographic recordings were made of maximal motor response at one given polarity of stimulus pulses; then the polarity of the pulse wasoreversed and the procedure repeated.

The latency time was measured from the stimgless artifact to the start of the action potential. The vadues obtained with the bipolar stimulating electrode at opposite polarity of stimulus pulses were averaged in calculatis the final value.

The distance from the centre of the bipolar stimulating electrode to each recording electrode was measured wi obstetric calipers, with the subject's arm at the side. Th procedure gave a more reliable value than did a surfage measurement by tape. The result was less influenced कy variations in position of the arm or shoulder and wass more constant on repeated measurements by the same $\overline{\sigma r}$ different examiners (Gassel and Diamantopoulis, 1964)

The temperature of the room in which the tests were performed was 21 to $23^{\circ} \mathrm{C}$.

Twenty-four normal subjects examined ranged from 15 to 62 years of age; five subjects were under 20 years of age and four over 50 years of age. Twenty-four patients were investigated. In most instances the patients had weafness or wasting of some muscles of the shoulder girdte; in some there was a history of polyneuritis with either little or no clinical evidence of proximal disease (see table).

\section{TERMINAL MOTOR INNERVATION}

The motor end plates of skeletal muscle are conces trated in a narrow zone at the middle of the muschle fibres in their course from origin to insertion. Te 
TABLE

Case Diagnosis

No.

Bulk ${ }^{1}$ and Latency Time ${ }^{2}$ of Muscle Tested

Remarks

\begin{tabular}{|c|c|c|c|c|c|c|c|c|c|}
\hline \multicolumn{2}{|l|}{ Deltoid } & \multicolumn{2}{|l|}{ Biceps } & \multicolumn{2}{|c|}{ Supraspinatus } & \multicolumn{2}{|c|}{ Infraspinatus } & \multicolumn{2}{|l|}{ Triceps } \\
\hline Atrophy & Latency & Atrophy & Latency & Atrophy & $\overline{\text { Latency }}$ & Atrophy & $\overline{\text { Latency }}$ & Atrophy & Latency \\
\hline$\}_{++}^{+++}$ & $\begin{array}{l}\mathbf{N} \\
\mathbf{N}\end{array}$ & $\stackrel{+}{0}$ & $\begin{array}{l}\mathbf{N} \\
\mathbf{N}\end{array}$ & $\stackrel{+\dagger \dagger}{+t}$ & $\begin{array}{l}\mathbf{N} \\
\mathbf{N}\end{array}$ & $\begin{array}{c}+t+ \\
++t\end{array}$ & $\underset{\mathbf{N}}{\mathbf{N}}$ & $+\dagger$ & $\mathbf{N}$ \\
\hline
\end{tabular}

2 sclerosis

3 Spinal cord tumour $\dagger \dagger$

4 Syringomyelia

5 Guillain-Barré disease $\mathbf{N} \quad+i \dagger \quad \mathbf{N}$

$\mathbf{N}+\mathbf{N}^{+} \mathbf{N}$

$\mathrm{O}$

P††

\} 0

$\mathbf{P}+\dagger$

O Pं

6 (acute stage)

$\mathrm{O}$

8

7 Recurrent

\}$_{0}^{0}$

$\begin{array}{ll}P+t+ & \mathbf{O} \\ \mathbf{P}++t^{+} & \mathbf{O}\end{array}$

$\mathbf{P}+\dagger+$

o

$\mathbf{P}+\dot{t+}$

O

P+十† O

$\mathbf{P}++\dagger$

8 polyneuritis

Pitt

$\mathrm{P}+\mathrm{P}^{\dagger}$

$\mathbf{P} \uparrow$

P+t+

\section{9}

$$
10
$$

11 neuritis

12

$\left\{\begin{array}{l}0 \\ 0 \\ 0 \\ 0\end{array}\right.$

P
N
N
N

$\mathrm{O}$
$\mathrm{O}$
$\mathrm{O}$
$\mathrm{O}$

P
N
N
N

$\begin{array}{llllll}0 & \mathbf{N} & \mathbf{O} & \mathbf{N} & \mathbf{O} & \mathbf{N} \\ \mathrm{O} & \mathrm{N} & \mathrm{O} & \mathrm{N} & & \end{array}$

\begin{tabular}{|c|c|c|c|c|}
\hline 13 & Brachial plexus injury & $++i$ & $\mathbf{P}$ & $\dot{+}$ \\
\hline 14 & Axillary nerve injury & $++\dot{+}$ & $\mathbf{P}$ & O \\
\hline $\left.\begin{array}{l}15 \\
16 \\
17 \\
18\end{array}\right\}$ & Shoulder neuritis & $\begin{array}{l}++\dagger \\
+ \\
+++ \\
+\dagger\end{array}$ & $\begin{array}{l}\mathbf{N} \\
\mathbf{N} \\
\mathbf{N} \\
\mathbf{P}\end{array}$ & ++ \\
\hline 19 & Cervical disc prolapse & ++ & $\mathbf{N}$ & +++ \\
\hline $\left.\begin{array}{l}20 \\
21\end{array}\right\}$ & $\begin{array}{l}\text { Muscular } \\
\text { dystrophy }\end{array}$ & $\stackrel{++\dagger}{+}$ & $\begin{array}{l}\mathbf{N} \\
\mathbf{N}\end{array}$ & $\stackrel{++\dagger}{+}$ \\
\hline $\left.\begin{array}{l}22 \\
23\end{array}\right\}$ & Myasthenia gravis & $\begin{array}{l}\mathrm{O} \\
\mathrm{O}\end{array}$ & $\stackrel{N}{N}$ & $\begin{array}{l}\mathrm{O} \\
\mathrm{O}\end{array}$ \\
\hline
\end{tabular}

${ }^{1}$ Atrophy graded as $\mathrm{O}=$ normal

$\dagger \rightarrow++\dagger=$ increasing degrees of atrophy

"Latency graded as $\mathbf{N}=$ normal

$\mathbf{P}=$ prolonged

$\dagger \rightarrow++\dagger=$ increasing degrees of prolongation

shape of the innervation zone depends on the pattern of distribution of the muscle fibres (Coërs and Wolff, 1959; Christensen, 1959). The deltoid is a multipennate muscle with fibres converging towards several insertion tendons. However, the fibres are largely longitudinally orientated with relatively little irregularity in the anterior and posterior parts of the muscle. The end plates form an irregular wavy but largely horizontally directed band in the muscle. The biceps brachii is composed of two separate unipennate muscles with long longitudinally directed

muscle fibres. The end plates are concentrated in a long horizontal band at the middle of the muscle; there is an additional small horizontal end plate band in the medial and distal part of the muscle where some shorter fibres are present in the short head of the muscle. The muscle fibres in the three heads of the triceps brachii muscle converge towards a large aponeurosis which begins near the middle of the muscle. The end plates are arranged in a long longitudinally orientated oval band, with the crown of the oval situated proximally (Christensen, 1959). 
The fibres of the supraspinatus and infraspinatus muscles course laterally and converge in a tendinous insertion; the muscles can be expected to have a predominantly longitudinally directed end plate band in the middle of the muscle.

\section{RESULTS}

ARTIFACTS OF PROCEDURE It was important to place the bipolar stimulating electrode at Erb's point, which is easily identified. It was demonstrated in two subjects that placement of the electrode $5 \mathrm{~cm}$. superio-medially resulted in about a $1 \mathrm{msec}$. increase in latency. The stimulus delivered should be adequate to produce a maximal motor response. It was found that a submaximal response might have a considerable increase in latency. Another pitfall of inadequate stimulation was the recording of an H-reflex. An H-reflex was elicited in three normal subjects by stimuli subthreshold for direct stimulation of the motor fibres; it occurred 10 to $14 \mathrm{msec}$. after stimulation, and might be misinterpreted as a prolongation in latency.

LATENCY VALUES IN NORMAL SUBJECTS These are described in five muscles.

Biceps brachii The latencies from 23 normal subjects are charted in Figure 1 . The mean value at $20 \mathrm{~cm}$. $(19-21 \mathrm{~cm}$.) is $4.6 \pm 0.14 \mathrm{msec}$. (S.D. $=0.6$ msec., $\mathrm{N}=19)$. The mean value at $24 \mathrm{~cm}$. $(23-25$ $\mathrm{cm}$.) is $4.7 \pm 0.15 \mathrm{msec}$. (S.D. $=0.6 \mathrm{msec}$., $\mathrm{N}=15)$; and that at $28 \mathrm{~cm} .(27-29 \mathrm{~cm}$.) is $5.0 \pm$ 0.13 msec. (S.D. $=0.5 \mathrm{msec}$., $\mathrm{N}=14$ ). The three latencies from each of five representative individuals are joined by lines. There are some small variations between the single latency times at different distances but no regular or systematic differences. Recording of the action potentials of a normal subject are illustrated in Figure 2a.

Deltoid muscle The latency times from 24 normal subjects are presented in Figure 3. The mean value at $15.5 \mathrm{~cm} .(15-16 \mathrm{~cm})$. from the point of stimulation is $4.3 \pm 0.11 \mathrm{msec}$. (S.D. $=0.5 \mathrm{msec}$., $\mathrm{N}=20$ ); and that at $18.5 \mathrm{~cm} .(18-19 \mathrm{~cm}$.) is $4.4 \pm 0.08 \mathrm{msec}$. (S.D. $=0.35 \mathrm{msec} ., \mathrm{N}=17$ ). The three latencies from each of five representative individuals are joined by lines. There are some small variations between the single latency times at different distances but no regular or systematic differences.

Triceps brachii There were 24 normal subjects tested (Figure 4). The mean value at $21.5 \mathrm{~cm}$. $(20-30 \mathrm{~cm}$.) from the point of stimulation is $4.5 \pm$ $0.1 \mathrm{msec}$. (S.D. $=0.42 \mathrm{msec}$., $\mathrm{N}=16$ ); that at $26.5 \mathrm{~cm}$. $(25-28 \mathrm{~cm}$.) is $4.9 \pm 0.1 \mathrm{msec}$. (S.D. $=$ $0.45 \mathrm{msec}$., $\mathrm{N}=23)$; and at $31.5 \mathrm{~cm} .(30-33 \mathrm{~cm}$.) the mean value is $5.3 \pm 0.12 \mathrm{msec}$. (S.D. $=0.5$
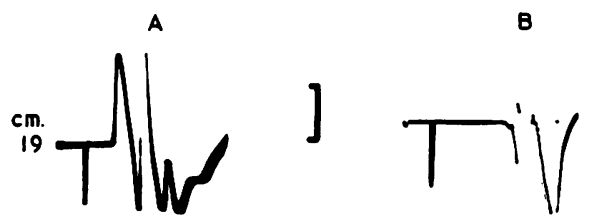

FIG. 2. Recordings of the action potentials from biceps brachii on stimulation at Erb's point in a 20-year: normal subject, $A$, and a 22-year-old patient with recurrent polyneuritis, $B$ (case 7 in Table and Figure 1).

msec., $N=16$ ). The three latencies from each of four representative individuals are joined by lines? There is an overall increase in the latency in the more $\overrightarrow{\vec{E}}$ distal recordings although the increase is not, in general, a regular and progressive one.

Supraspinatus muscle There were 23 normas. subjects tested (Figure 5). The mean value at $8.5 \mathrm{~cm}$ $(8-9 \mathrm{~cm}$.) is $2.6 \pm 0.07 \mathrm{msec}$. (S.D. $=0.32 \mathrm{msec}$ $\mathrm{N}=19)$ and that at $10.5 \mathrm{~cm} .(10-11 \mathrm{~cm}$.$) is 2.7$ 0.07 msec. (S.D. $=0.27, N=16$ ). There was $n \vec{\sigma}$ significant difference between the latency values in the individual examinations.

Infraspinatus muscle Twenty normal subjects were tested (Figure 6). The mean value at $14 \mathrm{~cm}$. (13-15 $\mathrm{cm}$.) is $3.4 \pm 0.09 \mathrm{msec}$. (S.D. $=0.4 \mathrm{msec} ., \mathrm{N}=20$ ) and at $17 \mathrm{~cm}$. $(16-18 \mathrm{~cm}$.) is $3.4 \pm 0.13$ msec (S.D. $=0.5 \mathrm{msec}$., $\mathrm{N}=15$ ). There were smalP variations in the individual results; eight of 20 sub今 jects had a slightly longer latency to the distal 

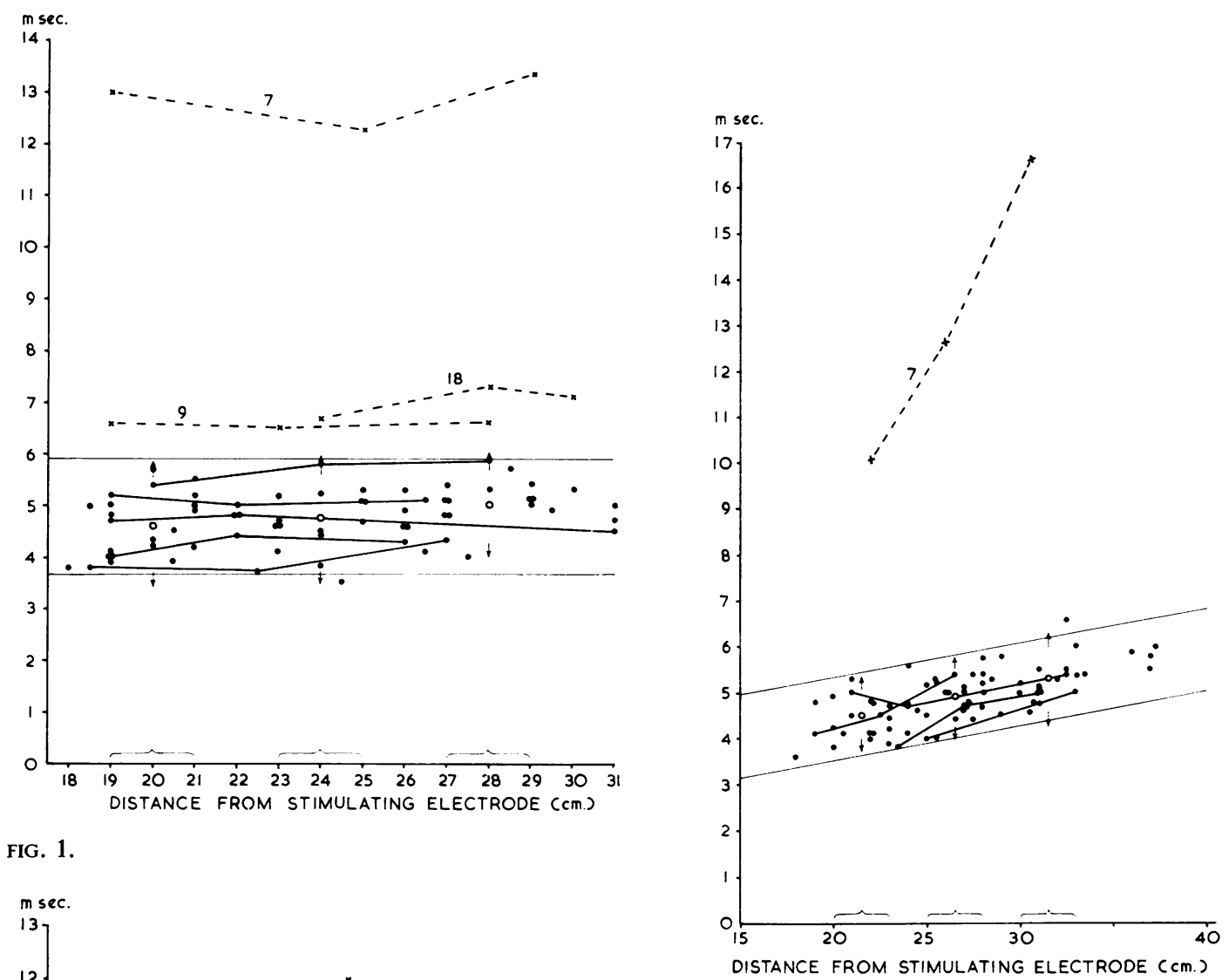

FIG. 1.

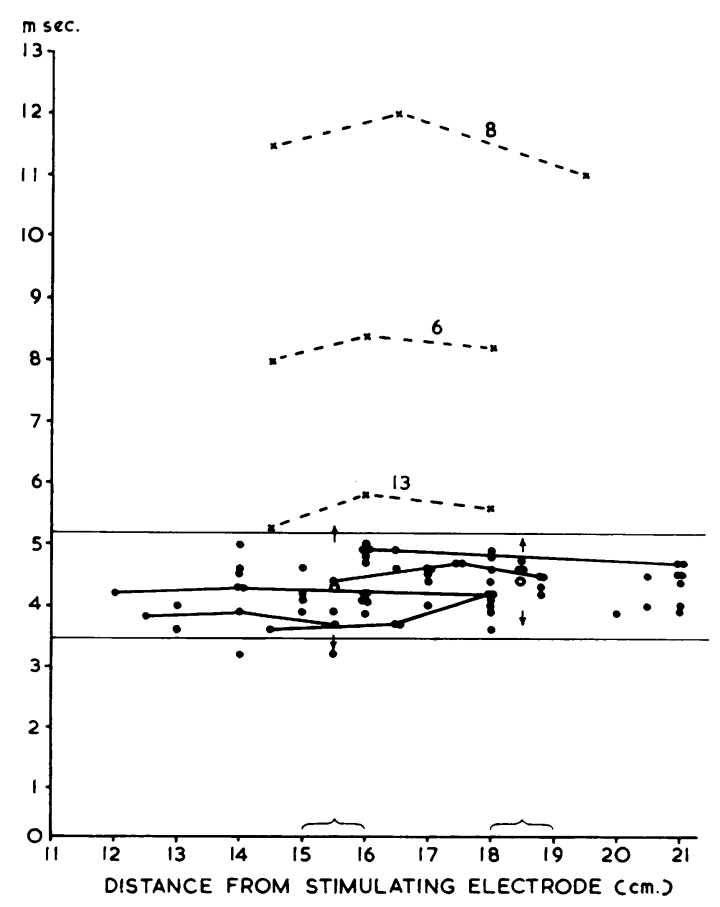

FIG. 4.

FIG. 1. Biceps brachii.

FIG. 3. Deltoid.

FIG. 4. Triceps.

The latency values in normal subjects are marked by dots. The mean values are marked with open circles; twice the standard deviations from the mean are indicated with arrows. The continuous thick lines enclose the normal range of values (mean values plus twice the standard deviations). The latencies from each of a number of normal subjects are joined by a continuous fine line.

Elevated latencies from representative patients are indicated by crosses, and the values from each patient are connected by a broken line. The numbers refer to the cases in the chart.

FIG. 3. 


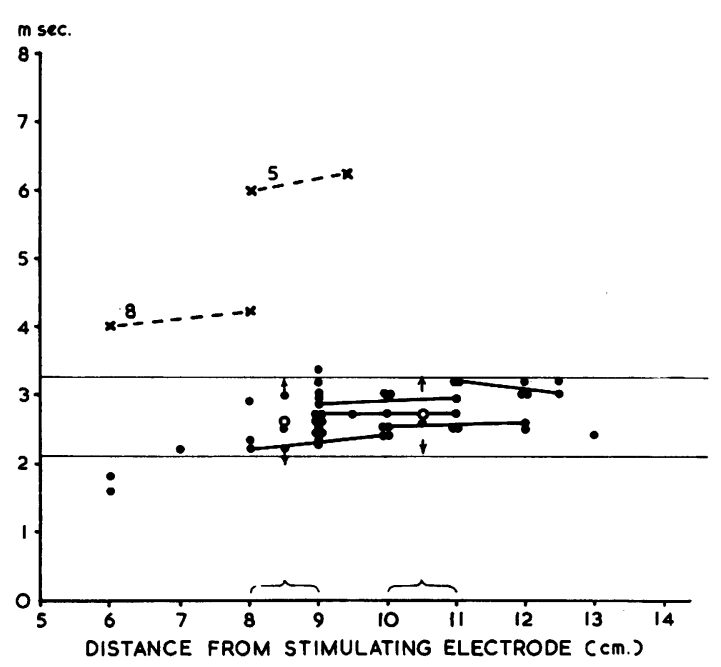

FIG. 5. Supraspinatus.

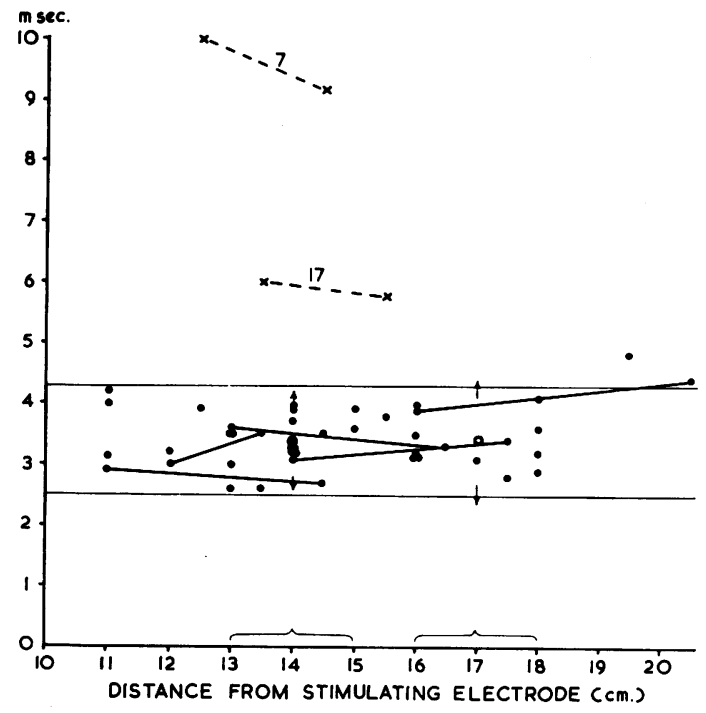

FIG. 6. Infraspinatus.

recording electrode, three had a slightly longer latency to the proximal electrode, and nine showed no difference.

RESULTS IN PATIENTS Elevated latency values were found in nine of 23 patients examined (Table, Figures 1 to 6). The elevation was most pronounced in two patients with recurrent polyneuritis and no muscular wasting or weakness, and in two patients with Guillain-Barré disease with severe generalized weakness but no wasting of muscles. Slight prolongation of values was found in one of four patients with peripheral neuritis with depression of all deep tendor reflexes but no other evidence of involvement of proximal muscles. A small increase in latency wa里 found in the wasted deltoid muscle of a patient witls a traumatic lesion of the axillary nerve whereas at other latency values were in the low normal range another patient with a brachial plexus lesion had a slightly prolonged latency to a severely waste deltoid but a normal latency to a severely wastect. supraspinatus muscle. Two of four patients wit shoulder neuritis had slight to moderate elevation of values in some muscles tested but latencies werẹ? normal in some severely wasted muscles. Norma latencies were found to moderately wasted muscles로 the result of a cervical disc prolapse. There was nop elevation of latency values in two patients witt primary muscle disease or in four patients with anterior horn cell disease, even in the presence of severe wasting of muscles; and latency time wa? normal in two patients with myasthenis gravis with severe weakness of the muscles tested.

\section{DISCUSSION}

RELATIONSHIP OF LATENCY TIME TO DISTRIBUTION ఫ్ END PLATE ZONE IN MUSCLE In the matter of relationship of the latency times to the end plate zone distribution, the individual records are more significant than the mean values. This is the because a longer latency in subjects with longer arms is to be expected, regardless of the distribution of end plate zone. This will result in an apparento increase in the latency in recordings at long distanges from the stimulating point.

The latency of the response from the biceps brachis and deltoid muscle showed no systematic change with distance from the point of stimulation. In these muscles the end plates are located largely in of horizontal band in the middle of the muscle and the latency recorded at any point in the muscle would be expected to be about the same.

In the triceps there was an increase in latency of the response with increasing distance from the point. of stimulation; and a similar finding was reportec in the rectus femoris muscle (Gassel, 1963). In these muscles the end plates form a vertically orientate oval; and the increase in latency with distance is probably due to the innervation of the distal part of the muscle by longer nerve branches.

The progression of increase in latency with in creasing distance was not so regular in the triceps as was found in the rectus femoris. It therefore seem possible that some of the branches innervating the triceps supply a relatively wide longitudinal zone of end plates on either side of entry into the muscle An alternative explanation is suggested by the finding 
of nerve fibres of larger diameter to the long head than to the medial head of the triceps muscle (Fernand and Young, 1951); and it is possible that the electrodes placed in the midline of the muscle may record potentials from either head of the triceps, resulting in some variability in the latency.

In the infraspinatus and supraspinatus there were small variations between latency values in the individual examinations, and no conclusive pattern of values was established.

PROLONGATION OF LATENCY Prolongation of latency was found only in patients with neuritis. However, normal values occurred in some wasted muscles which resulted from disease of the brachial plexus or nerve roots. The latency test is a measure of the fastest conducting fibres and if some of these are intact the value is likely to be within normal limits. This may be the explanation of normal values found in some severely wasted muscles due to a brachial plexus injury, and a similar interpretation applies in the case with cervical disc prolapse, particularly as a muscle is innervated by multiple roots and the prolapsed disc may not compress them all. The diversity of latency times in neuritis of the shoulder is difficult to interpret, but it is likely that this is a syndrome rather than an entity; and the site of the lesion has not been established (Höök, 1950).

The degree of prolongation of latency had no relationship to the extent of clinical abnormality of the muscles tested. Markedly prolonged latencies were found in patients with recurrent polyneuritis with muscles of normal bulk and power, although with depression of the tendon jerks; and the latencies were moderately increased in patients with GuillainBarré disease with severe generalized weakness but no muscle wasting.

The extent of prolongation of the latency was comparable to the extent of reduction of the motor conduction velocity in the patients with recurrent polyneuritis. However, in a patient with GuillainBarré disease (case 6), examined on three occasions at about weekly intervals after the onset of the illness, there was a normal conduction velocity in the arm, forearm, and distal segments of the ulnar nerve, whereas the latencies to the proximal muscles of the upper extremity were moderately elevated on each occasion. A similar situation prevailed in the second patient with Guillain-Barré disease (case 5) in whom the motor conduction velocity of the median nerve was normal and the distal latency increased. This suggests that the pattern of involvement of nerves may be characteristic for different disease processes.

The occurrence of mild degrees of proximal muscular weakness or wasting and diminution of tendon reflexes in association with carcinoma (Croft and Wilkinson, 1963) and diabetes (Lancet editorial, 1963) has been reported. There is considerable difference of opinion as to the pathology of the lesion in such cases because of difficulty in distinguishing minor manifestations of lower motor neurone involvement from minor degrees of a myopathy. It is possible that the test of latency to the proximal muscles of the upper limb may contribute to the different diagnosis.

\section{SUMMARY}

The trunks of the brachial plexus were stimulated supraclavicularly (at Erb's point) and the response recorded from electrodes situated at increasing distances from the point of stimulation in proximal muscles of the upper extremity. The latency of response in the triceps muscle increased with the distance from the stimulation point but the latency in the biceps brachii or deltoid muscle showed little change with distance. These findings were related to the anatomy of nerve supply and end plate organization in the muscle.

The normal range of latency values was described for the biceps brachii, deltoid, triceps, supraspinatus, and infraspinatus muscles. Prolonged latencies were found in patients with neuritis but not in those with primary muscle disease or spinal muscular atrophy.

It was found that the proximal latency might be prolonged without reduction of motor nerve conduction velocity to distal muscles; and it was suggested that the pattern of involvement of nerves may be characteristic for different diseases.

\section{REFERENCES}

Christensen, E. (1959). Amer. J. phys. Med., 38, 65.

Cöers, C., and Wolff, A. L. (1959). The Innervation of Muscle. Blackwell, Oxford.

Croft, P. B., and Wilkinson, M. (1963). Lancet, 1, 184.

Editorial (1963). Lancet, 2, 287.

Fernand, V. S. V., and Young, J. Z. (1951). Proc. roy. Soc. B, 139, 38. Gassel, M. M. (1963) Arch. Neurol. (Chic.), 9, 607.

and Diamantopoulis, E. (1964). Neurology (Minneap.), 14, 222. Höök, O. (1950). Acta psychiat. (Kbh.), 25, 209. 